\title{
Extraction and characterization of gelling pectin from the peel of Poncirus trifoliata fruit
}

\author{
Kouassi L. Koffi ${ }^{1}$, Beda M. Yapo ${ }^{2^{*}}$, V. Besson ${ }^{3}$ \\ ${ }^{1}$ Food Research Unit, Polytechnique National Institute of Felix Houphouet Boigny, Abidjan, Côte d'Ivoire \\ ${ }^{2}$ Subunit of Pedagogy in Biochemistry and Microbiology, University of Jean-Lourougnon Guédé, Daloa, Côte d'Ivoire; \\ *Corresponding Author: bedamarcel@yahoo.fr \\ ${ }^{3}$ Food Research and Technology Division, Cargill West Africa, Abidjan, Côte d'Ivoire
}

Received 6 August 2013; revised 26 September 2013; accepted 18 October 2013

Copyright (C) 2013 Kouassi L. Koffi et al. This is an open access article distributed under the Creative Commons Attribution License, which permits unrestricted use, distribution, and reproduction in any medium, provided the original work is properly cited.

\begin{abstract}
In the framework of searching for new pectin sources to partially compensate for domestic and regional demands, the peel (albedo) of the "non-comestible" fruit of Poncirus trifoliata was investigated using a relatively simple experimental design for optimization, in which only the variable was the extraction $\mathrm{pH}(1.0,1.5$, and 2.0$)$ on the basis of our previous studies on diverse pectin sources. The results showed that the yield of pectin $(7.4 \%-19.8 \%)$ was strongly influenced by the extraction $\mathrm{pH}$ when the other parameters, namely the solid to liquid extractant $(S / L)$ ratio, temperature $\left(T{ }^{\circ} \mathrm{C}\right)$, and time $(t)$ were fixed to $1: 25(\mathrm{w} / \mathrm{v}), 75^{\circ} \mathrm{C}$, and $90 \mathrm{~min}$, respectively. Likewise, the galacturonic acid content (GalA: $61.4 \%-79.2 \%$ ), total neutral sugar content (TNS: $9.1 \%$ - $22.5 \%)$, degree of branching (3.5\% $13.9 \%$ ), homogalacturonan (HG) to rhamnogalacturonan-I (RG-I) ratio (2.2 - 5.6), degree of methylesterification (DM: 54 - 77), viscosity average molecular weight ( $M_{v}: 57$ - 82), and gelling capacity (GC: 124 - 158) were all affected by the extraction $\mathrm{pH}$. The optimum $\mathrm{pH}$ for producing pectin with good yield, quality characteristics (GalA > $65 \%, \mathrm{DM}>60, M_{v}>80 \mathrm{kDa}$ ), and gelling capacity (GC $>150$ ), from the peel of $P$. trifoliata fruit, was found to be $\mathrm{pH} 1.5$.
\end{abstract}

Keywords: Poncirus trifoliata; Pectin; Block Copolymers; Macromolecular Characteristics; Gelling Strength

\section{INTRODUCTION}

Pectins are natural polysaccharides from all higher plant cell walls. They are generally composed of $\alpha$-Dgalactopyranosyluronic acid ( $\alpha$-D-GalpA), and three neutral sugars, namely $\alpha$-L-rhamnopyranose ( $\alpha$-L-Rha $p$ ), $\beta$-D-galactopyranose ( $\beta$-D-Gal $p)$, and $\alpha$-L-arabinofuranose ( $\alpha$-L-Araf). The different sugars are linked to one another in the way that gives rise to pectin structure with two-to-three block copolymers, viz. homogalacturonan (HG), type one rhamnogalacturonan (RG-I), and type two rhamnogalacturonan (RG-II) to a lesser extent. HG is an 1,4- $\alpha$-D-Gal $p$ A polymer esterified with methyl alcohol at $C-6$ position and sometimes with acetic acid at $O-2$ and/or $O-3$ positions. RG-I is an $[1,4)-\alpha-\mathrm{D}-\mathrm{Gal} p \mathrm{~A}-$ $1,2-\alpha$-L-Rhap- $(1,4]$ polymer, commonly branched with 1,5- $\alpha$-L-arabinan, 1,4- $\beta$-D-galactan, and type one arabinogalactan. RG-II is a rhamnose-containing polymer, which has an oligogalacturonan core branched with four well-defined side chains [1]. However, it remains a matter of debate if all the block copolymers are covalently linked to one another, and how they are likely interconnected to one another within pectin structure, due to insufficiency in the availability of compelling and irrefutable body of structural data. Nevertheless, it is worth underlying that three basic models have been proposed in the literature [2-4].

The main functional property so far known to pectins is their ability to form gelling systems under specified conditions $[5,6]$. It is now well known that the pectin $\mathrm{HG}$ domain is responsible for its gelling capability, while the pectin RG-I region chiefly plays a gel-stabilising role $[6,7]$. Two different gelling mechanisms have been described, depending on the methylesterification degree (DM) of pectins. Thus, high methylesterified pectins $(\mathrm{DM}>50 \%)$ are commonly used to prepare sugar-acidmediated gels (HMP-SAG) and low methyl-esterified pectins $(\mathrm{DM} \leq 50 \%)$ are utilized for the preparation of calcium-mediated (low calorie) gels. To date, commercial pectins, used for the preparation of different confec- 
tions and gelling products (such as marmalades, jams, preserves, and low calorie gels), are principally produced, in Europe and in the United States of America, from two pectin-rich sources (lime albedo and apple pomace) under specified industrial extraction conditions: dry raw material to solvent ratio $1: 35-1: 15(\mathrm{w} / \mathrm{v})$, water acidified with $\mathrm{HNO}_{3}$ (or $\mathrm{HCl}$ ) to $\mathrm{pH} 1.0$ - 3.0, temperature $60^{\circ} \mathrm{C}-100^{\circ} \mathrm{C}$, and time $30-180 \mathrm{~min}$. Thus, commercial pectin import in emerging and especially in developing countries to satisfy their demand represents a high cost operation with low added values to domestically manufactured gelling products. As a result, local food distribution firms in developing countries such as Côte d'Ivoire are thus compelled to import ready-to-eat gelling products. To partially remedy this problem, local agricultural byproducts, able to yield pectins with good gelling properties, are currently being searched for to compensate for the high cost linked with import of commercial lime and/or apple pectins. In this connection, the present study reports on the isolation and characterization of pectin with good yield, quality characteristics, and gelling capacity from the peel (albedo) of the underutilized Poncirus trifoliata fruit, a locally abundant and hitherto unexploited pectin source. The Poncirus fruit is a "noncomestible" fruit, because of its intense bitterness caused by the presence of poncirin and is so far locally processed by naturotherapeutists who commonly use the fruit seeds, juice and essential oil (from the flavedo) as traditional remedies against malaria and insect (mosquito and ant) bites.

\section{MATERIAL AND METHODS}

\subsection{Pectin Extraction}

Fresh peels (albedo and flavedo) of the fruit of Poncirus trifoliata were separately collected from a medium-size plant of local producers of Poncirus juice, seeds and essential oil, in a city named Bacon, located in the southeastern region of Cote d'Ivoire. The peels were immediately blanched to prevent enzymatic degradation of the cell wall pectins, and oven-dried to about $7 \%$ final moisture content. The dried peels were ground in a hammer mill (Model 912, Winona Attrition Mill Co., Winona, MN) to pass through a $12 \mathrm{~mm}$ mean diameter size sieve and kept under moisture-free conditions until utilisation.

Pectins were extracted only from the albedo using a relatively simple experimental design for optimization. On the basis of our previous work on other pectin sources, the solid to liquid (extractant) ratio $(\mathrm{S} / \mathrm{L})$, temperature $\left(\mathrm{T}{ }^{\circ} \mathrm{C}\right)$, and time $(\mathrm{t})$ were invariably fixed to $1: 25(\mathrm{w} / \mathrm{v}), 75^{\circ} \mathrm{C}$, and $90 \mathrm{~min}$, respectively, and only the extraction $\mathrm{pH}$ was varied from 1.0 to 2.0 per 0.5 unit interval (1.0, 1.5 and 2.0). The peel was extracted twice before discarding insoluble fraction. At the end of each extraction, the slurry was filtered and pectin extract was rapidly brought to $\mathrm{pH} 4$ for stability. The first and second extracts were combined, concentrated to desired volume, and then precipitated in 3 volumes of $95 \%$ ethanol at $5^{\circ} \mathrm{C}$ for $2 \mathrm{~h}$. Pectin precipitates were washed (twice) with $70 \%$ ethanol, followed by $95 \%$ ethanol and dry acetone, and kept for a while under a fume extractor (for residual acetone evaporation) and finally oven-dried at $45^{\circ} \mathrm{C}$ overnight and weighed. Extraction of pectins was performed in three independent runs for each $\mathrm{pH}$ value. Dried pectin flakes were finely ground to pass through 60 mesh $(0.25 \mathrm{~mm})$ size sifters. Pectin flours were canned in plastic containers and kept at room temperature under airless and moisture-free conditions until use.

\subsection{Pectin Characterization}

\subsubsection{Pectin Purification}

Prior to characterization, the pectin samples were treated with a mixture of $1 \%(\mathrm{v} / \mathrm{v}) \mathrm{HCl} / 60 \%(\mathrm{v} / \mathrm{v})$ ethanol (three times), and the remaining pectin fractions were exhaustively washed with $60 \%(\mathrm{v} / \mathrm{v})$ ethanol until the filtrate gave a negative response for chloride ions with silver nitrate, indicating that no free sugars were present within the so purified samples. This treatment indeed aimed at removing free sugars and salts and converting all the non-methylestrified carboxyl groups of pectin macromolecules to the free acid $(-\mathrm{COOH})$ form for a correct titration with $1 \mathrm{~N} \mathrm{NaOH}$. Commercial citrus high methoxy pectin (CCHMP: 95\% DM, Sigma-Aldrich Co., St. Louis, MO) was used for comparison, especially with regard to functional (gelling) properties, after enzymaticcontrolled partial desertification to $74 \%$ DM (with orange peel PME (P5400) Sigma-Aldrich Co. St. Louis, $\mathrm{MO}$ ), which did not significantly affect its sugar composition and molecular characteristics [7]. Pectins were characterized for the sugar composition, esterification degree, molecular weight, and gelling capacity.

\subsubsection{Pectin Analysis}

The GalA content of pectin samples was colorimetrically quantified at $525 \mathrm{~nm}$ by a modified sulfamatemeta-hydroxydiphenyl (MHDP) assay using monoGalA standard [8]. To assess the neutral sugar (NS) content, pectins were first hydrolyzed with $1 \mathrm{~mol} \cdot \mathrm{L}^{-1} \quad \mathrm{H}_{2} \mathrm{SO}_{4}$ $\left(100^{\circ} \mathrm{C}, 3 \mathrm{~h}\right)$ and freed NS, notably galactose/arabinose (Megazyme procedure) and rhamnose [9] were quantified spectrophotometrically at $340 \mathrm{~nm}$ using Megazyme assay kits (Megazyme International Ireland Ldt., Bray, Co. Wicklow, Ireland). The two NS assays were based on the quantitative oxidation of galactose/arabinose and rhamnose to corresponding lactonic derivatives (D-galactono-(1,4)-lactone for $\alpha$-L-Arabinose and $\beta$-D-Galactose and L-rhamno-(1,4)-lactone for $\alpha$-L-rhamnose) in 
the presence of corresponding dehydrogenases $(\beta$-galactose dehydrogenase $(\beta$-GalDH) plus galactose mutarotase (GalM) for $\alpha$-L-arabinose and $\beta$-D-galactose, and Lrhamnose dehydrogenase for $\alpha$-L-rhamnose) and the coenzyme $\mathrm{NAD}^{+}$, which is stoichiometrically reduced to $\mathrm{NADH}$ with maximum absorbance measured at $340 \mathrm{~nm}$. D-galactose was quantitatively differentiated from Larabinose by reading absorbance at different reaction times, viz. after 6 min- and 12 min-reaction at room temperature, respectively. L-rhamnose was quantitatively determined after $1 \mathrm{~h}$-reaction at room temperature. Total neutral sugar (TNS) was estimated either by the tri-reagent (anthrone, orcinol, and MHDP) colorimetric$\mathrm{H}_{2} \mathrm{SO}_{4}$ assay as reported previously [7] or by calculating the sum of the amounts of the three NS determined.

The molar ratio of HG to RG-I block copolymers was roughly estimated using relation 1 , reequated from previously published work $[1,10]$.

$$
\text { HG } / \text { RG-I }(\%)=100 \times \frac{[\operatorname{GalA}(\%)-\operatorname{Rha}(\%)]}{[2 \mathrm{Rha}(\%)+\operatorname{Ara}(\%)+\operatorname{Cal}(\%)]}
$$

The degree of branching ( $\mathrm{DBr}$ ) of pectins rhamnosyl residues with arabinose- and galactose-containing side chains was roughly estimated, by Equation (2), as previously reported [11].

$$
\mathrm{DBr}=100 \times \mathrm{Rha}(\%) /(\operatorname{Ara}(\%)+\operatorname{Gal}(\%))
$$

It expressed the minimum number of rhamnosyl residues per 100 arabinosyl and galactosyl residues of pectin, which should be distinguished from the minimum length of arabinose- and galactose-containing side chains. The lower the $\mathrm{DBr}$, the higher the level of branching of the pectin rhamnosyl residues.

The overall esterification degree of pectins was potentiometrically determined as previously described [12]. The acetylesterification degree (DAc) was colorimetrically measured at $510 \mathrm{~nm}$ by the hydroxamic acid assay using glucose pentaacetate standard [13], and the methylesterification degree (DM) was differentially evaluated. All the measurements were performed in triplicates.

The molecular weight of pectin samples was analysed by GFC on a high resolution Superdex-200 HR 10/30 column (Amersham Biosciences Corp., NJ). A molecular weight kit of pullulan standards $\left(M_{w} \sim 6.0,10.0,21.7\right.$, $48.8,113.0,210.0,393.0$, and $805.0 \mathrm{kDa} ; M_{w} M_{w} / M_{n}$ 1.0-1.2) from American Polymer Standards Corp. (Mentor, $\mathrm{OH})$ and homogenous HG standards $\left(M_{w} \sim 60\right.$ and $\left.100 \mathrm{kDa}, M_{w} / M_{n} \sim 1.0-1.2\right)$ [14] with known intrinsic viscosity ([ $\eta])$ and $M_{w}$ values were used for calibration. To better evaluate the pectin $M_{v}$, the so-called universal calibration technique (UCT) was used by plotting $\log \left([\eta] \times M_{w}\right)$ versus the elution volume $\left(V_{e}\right)$ of standards. Analyses were performed in triplicates.

\subsection{Gelling Properties}

The gelling capacity (or power) of pectins was evaluated by the determination of the strength of gels prepared under the following conditions: $65.0 \%$ soluble solids (sucrose), $0.70 \mathrm{wt} \%$ pectin, $\mathrm{pH} 2.3$, as previously described [12].

\subsection{Statistical Analysis}

The data were statistically evaluated by the global test of a single-factor analysis of variance (ANOVA), followed by the Bonferroni's posthoc test for multiple comparisons, whenever applicable, using a GraphPad Prism V.3 software (GraphPad software Inc., San Diego, CA). Means of different treatments were considered significantly different at $p<0.05$.

\section{RESULTS AND DISCUSSION}

\subsection{Extraction Yield of Pectins}

The yield of extracted pectins from the peel $P$. trifoliata fruit is shown in Table 1. The yield varied from $7.4 \%$ to $19.8 \%$ as the $\mathrm{pH}$ was varied from 1.0 to 2.0 , indicating that the yield of pectins was strongly pH-dependent when the other extraction parameters (solid to liquid ratio $(\mathrm{S} / \mathrm{L})$, temperature $\left(\mathrm{T}{ }^{\circ} \mathrm{C}\right)$, and time $\left.(\mathrm{t})\right)$ were kept constant. The different pectin yields were significantly different from one another $(p<0.05)$. The yield $(12.6 \%)$ obtained at $\mathrm{pH} 2.0$ was lower than the yield $(19.8 \%)$ obtained at $\mathrm{pH} 1.5$, suggesting that the yield tended to increase with increase in the strength of (acid) extracting agent. However, the yield of pectin substantially decreased as the strength of extractant was further increased up to $\mathrm{pH} 1.0$. This unexpected drastic drop in the yield of pectin extracted at $\mathrm{pH} 1.0$ could only be explained by considerable degradation of pectin polymers, during solubilization from the cell wall, into smaller oligomers, which were ethanol-soluble, and therefore were not precipitated in the final sample. This observation is consistent with various previous studies in which notable degradation of pectins in hot acid media was reported [15-17]. In the light of the differences observed in yields, the extraction conditions of $\mathrm{S} / \mathrm{L}(1: 25 \mathrm{w} / \mathrm{v}), \mathrm{T}\left(75^{\circ} \mathrm{C}\right), t$ (90 $\mathrm{min}$ ), and $\mathrm{pH} 1.5$ appeared to be the optimum conditions for isolating pectin with good yield from the peel (albedo) of P. trifoliata fruit.

\subsection{Characteristics of Extracted Pectins}

\subsubsection{Sugar Composition and Block Copolymers}

The sugar composition of the extracted pectins is also shown in Table 1. The galacturonic acid (GalA) content of pectins ranged from $61.4 \%$ to $79.2 \%$ as the extraction $\mathrm{pH}$ was varied from $\mathrm{pH} 1.0$ to $\mathrm{pH}$ 2.0. The pectin GalA amounts were significantly different from one another $(p$ 
Table 1. Sugar composition and molecular characteristics of extracted pectins from Poncirus peel.

\begin{tabular}{|c|c|c|c|c|}
\hline & \multicolumn{3}{|c|}{ PTP } & \multirow{2}{*}{ СCHMP } \\
\hline & $\mathrm{pH} 1.0$ & pH 1.5 & pH 2.0 & \\
\hline Yield (\%) & $7.4 \pm 1.2 \mathrm{a}$ & $19.8 \pm 2.5 b$ & $12.6 \pm 1.6 \mathrm{c}$ & \\
\hline $\operatorname{GalA}(\% \mathrm{w} / \mathrm{w})$ & $61.4 \pm 2.7 \mathrm{a}$ & $79.2 \pm 3.1 \mathrm{~b}$ & $67.2 \pm 2.5 \mathrm{c}$ & $85.2 \pm 2.7 \mathrm{~d}$ \\
\hline Rha $(\% \mathrm{w} / \mathrm{w})$ & $0.3 \pm 0.1 \mathrm{a}$ & $1.7 \pm 0.2 b$ & $2.6 \pm 0.8 \mathrm{c}$ & $0.9 \pm 0.2 \mathrm{~d}$ \\
\hline Ara $(\% \mathrm{w} / \mathrm{w})$ & $3.1 \pm 0.4 \mathrm{a}$ & $4.3 \pm 0.8 \mathrm{a}$ & $7.6 \pm 1.4 b$ & $2.2 \pm 0.5 \mathrm{a}$ \\
\hline Gal (\% w/w) & $5.7 \pm 1.2 \mathrm{a}$ & $8.2 \pm 1.1 \mathrm{a}$ & $12.5 \pm 1.7 \mathrm{c}$ & $5.1 \pm 1.2 \mathrm{a}$ \\
\hline TNS $(\% \mathrm{w} / \mathrm{w})$ & $9.1 \pm 0.8 \mathrm{a}$ & $14.2 \pm 0.9 \mathrm{~b}$ & $22.7 \pm 1.5 \mathrm{c}$ & $8.2 \pm 0.7 \mathrm{a}$ \\
\hline Rha/GalA & $0.6 / 100$ & $2.5 / 100$ & $4.6 / 100$ & $1.3 / 100$ \\
\hline $\operatorname{DBr}(\%)$ & $3.5 \pm 0.4 \mathrm{a}$ & $13.9 \pm 1.4 \mathrm{~b}$ & $13.4 \pm 1.6 \mathrm{~b}$ & $12.7 \pm 1.2 b$ \\
\hline HG (mol\%) & $84.7 \pm 1.3 \mathrm{a}$ & $80.5 \pm 2.1 b$ & $68.5 \pm 3.4 \mathrm{c}$ & $88.7 \pm 1.5 \mathrm{a}$ \\
\hline RG-I (mol\%) & $15.3 \pm 1.1 \mathrm{a}$ & $19.5 \pm 1.7 b$ & $31.5 \pm 1.2 \mathrm{c}$ & $11.3 \pm 1.6 \mathrm{a}$ \\
\hline HG/RG (\%) & $5.6 \pm 1.2 \mathrm{a}$ & $4.1 \pm 0.9 \mathrm{a}$ & $2.2 \pm 0.3 b$ & $7.9 \pm 1.1 \mathrm{a}$ \\
\hline DM & $54 \pm 6 a$ & $77 \pm 3 b$ & $63 \pm 2 c$ & $74 \pm 1 \mathrm{c}$ \\
\hline DAc & $\mathrm{Tr}$ & $4 \pm 1$ & $7 \pm 2$ & $\operatorname{Tr}$ \\
\hline$[\eta](\mathrm{mL} / \mathrm{g})$ & $201 \pm 8 a$ & $327 \pm 6 b$ & $281 \pm 5 c$ & $378 \pm 7 d$ \\
\hline$M_{v}(\mathrm{kDa})$ & $57 \pm 15 \mathrm{a}$ & $82 \pm 5 b$ & $68 \pm 6 c$ & $89 \pm 3 b$ \\
\hline $\begin{array}{l}\text { Gelling power } \\
\quad\left({ }^{\circ} \text { sag }\right)\end{array}$ & $124 \pm 2 \mathrm{a}$ & $158 \pm 3 b$ & $142 \pm 2 c$ & $179 \pm 5 d$ \\
\hline
\end{tabular}

Data are expressed as mean $\pm \mathrm{SD}(n=3)$. Mean values in the same line with different letters are significantly different $(p<0.05)$. Tr: trace $<0.05 \%$; PTP: Poncirus trifoliata pectin. CCHMP: Commercial citrus high methoxy pectin.

$<0.05)$. The highest amount of GalA was obtained at $\mathrm{pH}$ 1.5 and the lowest at $\mathrm{pH} 1.0$. This is likely to support the hypothesis that higher degradation of isolated pectin polymers into shorter oligomers occurred at $\mathrm{pH} 1.0$ than at the remainder $\mathrm{pH}$ values. In general, the GalA content of pectin (PTP) from the peel of $P$. trifoliata fruit was less great, compared to commercial citrus high methoxy pectin (CCHMP).

The three individual NS, quantified in all the PTP isolates, were galactose (Gal: 5.7\% - 12.5\%), arabinose (Ara: $3.1 \%$ - 7.6\%), and rhamnose (Rha: $0.3 \%-2.6 \%$ ), and the amount of total neutral sugar (TNS), calculated as the sum of the three NS, was in the range of $9.1 \%$ $22.7 \%$. Also, evaluation of TNS by the tri-reagent method revealed appreciable amounts of NS other than the three mentioned above (probably xylose and glucose from neighbouring polysaccharides such as xyloglucans) within the $\mathrm{pH} 2.0$-isolate, but not in the other two isolates. Hence, all the pectin samples, with the exception of the $\mathrm{pH}$ 2.0-isolate were highly purified. The amounts of TNS in all the PTP isolates were significantly different $(p$
$<0.05)$ from one another, though some individual NS were present in similar amounts. PTP isolated at $\mathrm{pH} 1.0$ had the lowest NS content $(9.1 \%)$ and PTP isolated at $\mathrm{pH}$ 2.0 had the highest NS content $(22.5 \%)$. This showed that pectin extraction at $\mathrm{pH} 1.0$ indeed resulted in substantial degradation of solubilized pectin macromolecules, mainly in their NS-containing RG-I regions. This was further confirmed by the observation that the $\mathrm{pH}$ 1.0-PTP isolate had a much lower $\mathrm{DBr}$ value $(\sim 3.5 \%)$, compared with the other two PTP samples ( $\mathrm{DBr} \sim 13.5 \%$ - 13.9\%) and even with CCHMP ( 12.7\%) to which it had a similar TNS content. Rapid degradation of the pectin NS (especially furanosyl residues) in hot acid media, due to high lability and sensitivity to acid, is a wellknown and documented phenomenon [15-17]. The difference in $\mathrm{DBr}$ between the PTP isolated at $\mathrm{pH} 1.0$ and CCHMP, to which it had similar TNS content $(8.2 \%$ $9.1 \%$ ), was mainly accounted for by discrepancy in the amount of rhamnose, which was three-time greater in latter pectin sample than in the former. This suggested that the rhamnosyl residues of the RG-I block copolymers of PTP might be scarcely branched with NS side chains within the cell wall, thereby rendering them more accessible and sensitive to acid cleavage. In general, galactose appeared to be the major NS in all the pectin samples, followed by arabinose, indicating that neutral branches were dominantly (arabino) galactans.

In all the pectin samples, the amount of $\mathrm{HG}$ was $>50 \%$ $(68.5 \%-84.7 \%)$, indicating that this block copolymer was predominant over RG-I within the pectin structure, assuming that no free (non-interlinked) polymer stretches were present. It is, indeed, known that peels (albedo) of mature fruits from the Citrus genus such as orange, lime, lemon, and grapefruit (of the Rutaceae family) are pectin HG-rich sources as also found here for the peel of mature fruit from the Poncirus genus. The HG to RG-I ratio varied from 2.2 (in pH 2.0-isolate) to 5.6 (in $\mathrm{pH} 1.0$-isolate), suggesting the presence of at least two-to-six HG per one RG-I block copolymers.

\subsubsection{Esterification Degree}

The degree of methylesterification (DM) of extracted pectins varied from 54 to 77 (Table 1), indicating that the pectin polymers within the albedo of the mature fruit of $P$. trifoliata are highly methylesterified. The highest value of DM was obtained at $\mathrm{pH} 1.5$ and the lowest at $\mathrm{pH} 1.0$. This may be explained by degradation of pectin estergroups under more severe extraction conditions. In all cases, the degree of acetylesterification (DAc) was rather low $(<10 \%)$. Pectin from the citrus genus is also naturally of a low DAc. In the light of these results, the extraction conditions of $\mathrm{S} / \mathrm{L}(1: 25 \mathrm{w} / \mathrm{v}), \mathrm{T}\left(75^{\circ} \mathrm{C}\right), t(90$ $\mathrm{min}$ ), and $\mathrm{pH} 1.5$ proved to be the best for isolating pectin with high GalA content $(>65 \%)$ and DM $(>60 \%)$, 
from the peel of $P$. trifoliata fruit, two of the quality characteristics that need to be fulfilled for possible mass production and marketing.

\subsubsection{Macromolecular Features}

The intrinsic viscosity ([ $\eta]$ ) of PTP varied from 201 to $327 \mathrm{~mL} / \mathrm{g}$ (Table 1), with the $\mathrm{pH} 1.0-\mathrm{PTP}$ and $\mathrm{pH} 1.5$ PTP isolates possessing the lowest and highest intrinsic viscosities, respectively $(p<0.05)$. Nevertheless, these intrinsic viscosities were great enough, suggesting that PTP macromolecules probably had an overall extended rod-like conformation, as imposed by the dominance of HG over NS-ramified RG-I block copolymers, rather than a compact sphere-like conformation. Likewise, the viscosity-average molecular weight $\left(M_{v}\right)$ of PTP varied from 57 to $82 \mathrm{kDa}$ (Table 1), with the pH 1.0-PTP and $\mathrm{pH}$ 1.5-PTP isolates exhibiting the lowest and highest values, respectively $(p<0.05)$. Both results definitively substantiated the fact that the extraction condition using $\mathrm{pH} 1.0$ induced higher degradation of pectin polymers than the remainder, and that the extraction condition using $\mathrm{pH} 1.5$ was more suitable for producing PTP with a $M_{v}$ comparable to that of CCHMP having a similar DM.

\subsection{Gelling Properties of Extracted Pectins}

The gelling capacity of PTP varied from 124 to 158 (Table 1). The $\mathrm{pH}$ 1.0-PTP and $\mathrm{pH}$ 1.5-PTP isolates displayed the lowest and highest values, respectively. This difference could be attributed to discrepancy in GalA content, DM, and $M_{v}$. The gelling capability of pectin is (one of) the most important factor(s) for labeling as a food additive and international marketing.

To date, only citrus (lime) peel and apple pomace are used for the production of commercial pectins in Western countries, mainly because citrus and apple pectins possess high gelling strengths $[5,6]$ in addition for the two raw materials to being available in large quantities. However, new sources such as mango and yellow passion fruit rinds are more and more domestically used in different emerging and developing countries such as India, Brazil, and South Africa to a lesser extent to partially solve the problem of high cost pectin import-low added value to locally manufactured gelling products. Our results showed that pectin with good yield, quality characteristics and gelling capacity (amply comparable to the benchmark citrus pectin) can be produced from the peel of underutilized Poncirus trifoliata fruit.

\section{CONCLUSION}

This study shows that Poncirus peel is a pectin-rich source. About $20 \%$ pectin isolate, with a high galacturonic acid content ( $>65 \%$ ), methylesterification degree $(>60 \%)$, viscosity-average molecular weight $(>80 \mathrm{kDa})$, and good gelling capability $(>150)$ can be produced under the optimum extraction conditions of 1:25-solid to solvent ratio, $75^{\circ} \mathrm{C}$-temperature, 90 min-time, and $\mathrm{pH}$ 1.5. Our future investigation should mainly focus on the rheological (viscoelastic) properties of the $\mathrm{pH} 1.5$-pectin isolate to find out the optimum conditions (temperature, time, and velocity) of gelation for possible small-size industrial production to satisfy the increasing indoors and outdoors demands at a reasonable cost.

\section{ACKNOWLEDGEMENTS}

We are indebted to Cargill West Africa for some financial support.

\section{REFERENCES}

[1] Yapo, B.M. (2011) Rhamnogalacturonan-I: A structurally puzzling and functionally versatile polysaccharide from plant cell walls and mucilages. Polymer Reviews, 51, 391-413.

http://dx.doi.org/10.1080/15583724.2011.615962

[2] Schols, H.A. and Voragen, A.G.J. (1996) Complex pectins: Structure elucidation using enzymes. In: Visser, J. and Voragen A.G.J., Eds., Pectins and Pectinases, Progress in Biotechnology, Elsevier Science, Amsterdam, 3-19. http://dx.doi.org/10.1016/S0921-0423(96)80242-5

[3] Vincken, J.P., Schols, H.A., Oomen R.J.F.J., McCann, M.C., Ulvskov, P., Voragen, A.G.J. and Visser, R.G.F. (2003) If homogalacturonan were a side chain of rhamnogalaturonan I. Implications for cell wall architecture. Plant Physioliogy, 132, 1781-1789.

http://dx.doi.org/10.1104/pp.103.022350

[4] Yapo, B.M. (2011) Pectic substances: From simple pectic polysaccharides to complex pectins - A new hypothetical model. Carbohydrate Polymers, 86, 373-385.

http://dx.doi.org/10.1016/j.carbpol.2011.05.065

[5] May, C.D. (1990) Industrial pectins: Sources, production and applications. Carbohydrate. Polymers, 12, 79-99. http://dx.doi.org/10.1016/0144-8617(90)90105-2

[6] Voragen, A.G.J., Pilnik, W., Thibault, J.-F., Axelos, M.A.V. and Renard, C.M.G.C. (1995) Pectins. In: Stephen, A.M., Ed., Food polysaccharides and Their Applications, Marcel Dekker, New York, 287-339.

[7] Yapo B.M. and Koffi K.L. (2013) Utilisation of model pectins reveals the effect of demethylated block size frequency on calcium gel formation. Carbohydrate Polymers, 92, 1-10. http://dx.doi.org/10.1016/j.carbpol.2012.09.010

[8] Yapo, B.M. (2010) Improvement of the compositional quality of monocot pectin extracts contaminated with glucuronic acid-containing components using a step-wise purification procedure. Food and Bioproducts Processing, 88, 283-290. http://dx.doi.org/10.1016/j.fbp.2009.07.001

[9] Turecek, P.L., Buxbaum, E. and Pittner, F. (1989) Quantitative determination of pectic substances as an example of a rhamnopolysaccharide assay. Journal of Biochemical and Biophysical Methods, 19, 215-222.

http://dx.doi.org/10.1016/0165-022X(89)90028-6 
[10] M'sakni N.H., Majdoub, H., Roudesli, S., Picton, L., Le Cerf, D., Rihouey, C. and Morvan, C. (2006) Composition, structure and solution properties of polysaccharides extracted from leaves of Mesembryanthenum crystallinum. European Polymer Journal, 42, 786-795. http://dx.doi.org/10.1016/j.eurpolymj.2005.09.014

[11] Yapo, B.M. and Koffi, K. L. (2006) Yellow passion fruit rind-A potential source of low-methoxyl pectin. Journal of Agriculture and Food Chemistry, 54, 2738-2744. http://dx.doi.org/10.1021/jf052605q

[12] Yapo, B.M. (2009) Biochemical characteristics and gelling capacity of pectin from yellow passion fruit rind as affected by acid extractant nature. Journal of Agriculture and Food Chemistry, 57, 1572-1578. http://dx.doi.org/10.1021/jf802969m

[13] McComb, E.A. and McCready, R. M. (1957). Determination of acetyl in pectin and in acetylated carbohydrate polymers. Analytical Chemistry, 29, 819-821. http://dx.doi.org/10.1021/ac60125a025

[14] Yapo, B.M. (2009) Pineapple and banana pectins com- prise fewer homogalacturonan building blocks with a smaller degree of polymerization as compared with yellow passion fruit and lemon pectins: Implication for gelling properties. Biomacromolecules, 10, 717-721. http://dx.doi.org/10.1021/bm801490e

[15] Canteri-Schemin, M.H., Fertonani, H.C.R., Waszczynskyj, N. and Wosiacki, G. (2005) Extraction of pectin from apple pomace. Brazilian Archives of Biology and Technology, 48, 259-266. http://dx.doi.org/10.1590/S1516-89132005000200013

[16] Garna, H., Mabon, N., Nott, K., Wathelet, B. and Paquot, M. (2006) Kinetic of the hydrolysis of pectin galacturonic acid chains and quantification by ionic chromatography. Food Chemistry, 96, 477-484. http://dx.doi.org/10.1016/j.foodchem.2005.03.002

[17] Yapo, B.M., Robert, C., Etienne, I., Wathelet, B. and Paquot, M. (2007) Effect of extraction conditions on the yield, purity and surface properties of sugar beet pulp pectin extracts. Food Chemistry, 100, 1356-1364. http://dx.doi.org/10.1016/j.foodchem.2005.12.012 